CARDIOVASCULAR MEDICINE

\title{
Ethnic variations in female vulnerability after an acute coronary event
}

\author{
K H Mak, J D Kark, K S Chia, L L Sim, B H Foong, Z P Ding, R Kam, S K Chew
}

Heart 2004;90:621-626. doi: 10.1136/hrt.2003.019307

See end of article for authors' affiliations ....................

Correspondence to: Dr K H Mak, Department of Cardiology, National Heart Centre, 17 Third Hospital Avenue,

Singapore 168752; mak koon hou@ nhc.com.sg

Accepted 12 December 2003

\begin{abstract}
Objective: To determine the ethnic variation of short and long term female vulnerability after an acute coronary event in a population of Chinese, Indians, and Malays.

Design: Population based registry.

Patients: Residents of Singapore between the ages of 20-64 years with coronary events. Case identification and classification procedures were modified from the MONICA (monitoring trends and determinants in cardiovascular disease) project.

Main outcome measures: Adjusted 28 day case fatality and long term mortality.

Results: From 1991 to 1999, there were 16320 acute coronary events, including 3497 women. Age adjusted 28 day case fatality was greater in women $(51.5 \% \vee 38.6 \%, p<0.001)$, with a larger sex difference evident among younger Malay patients. This inequality between the sexes was observed in both the pre-hospitalisation and post-admission periods. Among hospitalised patients, women were older, were less likely to have suffered from a previous $Q$ wave or anterior wall myocardial infarction, and had lower peak creatine kinase concentrations. Case fatality was higher among women, with adjusted hazard ratios of 1.64 (95\% confidence interval (Cl) 1.43 to 1.88 ) and 1.50 (95\% Cl 1.37 to 1.64 ) for 28 day and mean four year follow up periods. There were significant interactions of sex and age with ethnic group $(p=0.017)$. The adjusted hazards for mortality among Chinese, Indian, and Malay women versus men were 1.30, 1.71, and 1.96, respectively. The excess mortality among women diminished with age.

Conclusion: In this multiethnic population, both pre-hospitalisation and post-admission case fatality rates were substantially higher among women. The sex discrepancy in long term mortality was greatest among Malays and in the younger age groups.
\end{abstract}

W hile acute myocardial infarction (MI) occurs more commonly among men, several studies have shown that short term mortality after the event is higher among women. ${ }^{12}$ A review of 27 studies concluded that the reasons for increased early mortality among women were older age and the presence of other unfavourable baseline clinical characteristics. ${ }^{3}$ Long term survival was shown to be better for women after adjusting for differences in age and other covariates in large MI population registries. ${ }^{3}$ Subsequent investigators found an interaction between sex and age, ${ }^{4-7}$ with a female excess of mortality among younger patients $(<50$ years of age $)$ that diminished with age. Survival was similar between the sexes among the elderly ( $>70$ years of age).

The higher early mortality among hospitalised women may also be attributed to a difference in survival pattern after an acute coronary event. Among those who died within 28 days in the Scottish MONICA (monitoring trends and determinants in cardiovascular disease) population of Glasgow, ${ }^{8}$ men were more likely to die out of hospital $(74.3 \% \vee 67.8 \%$; $\mathrm{p}=0.0004)$. After hospitalisation, women were more likely to die, resulting in a similar 28 day case fatality rate between men $(49.8 \%)$ and women $(48.5 \%)$. However, in the MONICA project of 37 populations in 21 countries, the association between sex and MI outcome was inconsistent, ${ }^{9}$ varying between populations. We have shown strong ethnic differences both in the incidence of MI and in case fatality in Singapore. ${ }^{10}$ There may also be ethnic differences in the degree of sex discrepancy in mortality after MI in the context of a health care system that enables equal access to all Singapore citizens. Therefore, we compared short and long term coronary case fatality between men and women among Chinese, Indians, and Malays to determine the relation between excess female mortality after an acute coronary event.

\section{METHODS}

Case identification and determination

The method adopted by the Singapore Myocardial Infarction Register (SMIR) has been described. ${ }^{11}$ Briefly, it is a comprehensive population based register for all Singapore residents aged 20-64 years. Potential cases of MI, both in and out of hospital, were identified from discharge listings from all hospitals in Singapore (based on the International classification of diseases, 9th revision, codes 410 to 414), creatine kinase (CK) listings, the Registry of Births and Deaths, and postmortem reports. All pathology laboratories in Singapore submitted a quarterly listing of patients with $\mathrm{CK} \geqslant 400 \mathrm{IU} / \mathrm{l}$. It is a statutory requirement for all deaths to be reported within 24 hours of occurrence. All patients who were certified to have died of acute MI (usually out of hospital) were identified from the Registry of Births and Deaths. Necropsy reports were obtained where available. A structured questionnaire was also sent to the physician who certified out of hospital death to determine the events, symptoms, and signs before death. Trained investigators then rigorously evaluated all the reports of potential cases.

Demographic characteristics and clinical presentation were documented. However, this information was not available for a substantial number of patients who died out of hospital. Patient ethnicity was obtained from the source of

Abbreviations: $\mathrm{Cl}$, confidence interval; $\mathrm{Ml}$, myocardial infarction; MONICA, monitoring trends and determinants in cardiovascular disease; NRMI-2, National Registry of Myocardial Infarction 2; SMIR, Singapore Myocardial Infarction Register 
Table 1 Acute coronary events and 28 day case fatality by age and sex

\begin{tabular}{|c|c|c|c|c|}
\hline \multirow[b]{2}{*}{ Age (years) } & \multicolumn{2}{|l|}{ Men } & \multicolumn{2}{|l|}{ Women } \\
\hline & Events & Deaths & Events & Deaths \\
\hline $20-24$ & 14 & $5(35.7 \%)$ & 5 & $3(60.0 \%)$ \\
\hline $25-29$ & 45 & $16(35.6 \%)$ & 4 & $2(50.0 \%)$ \\
\hline $30-34$ & 232 & $72(31.0 \%)$ & 20 & $10(50.0 \%)$ \\
\hline $35-39$ & 628 & $182(29.0 \%)$ & 40 & $20(50.0 \%)$ \\
\hline $40-44$ & 1311 & $348(26.5 \%)$ & 127 & $62(48.8 \%)$ \\
\hline $45-49$ & 1874 & $533(28.4 \%)$ & 301 & $142(47.2 \%)$ \\
\hline $50-54$ & 2300 & $764(33.2 \%)$ & 485 & 234 (48.2\%) \\
\hline $55-59$ & 2888 & $1188(41.1 \%)$ & 992 & 503 (50.7\%) \\
\hline $60-64$ & 3531 & $1838(52.1 \%)$ & 1523 & 881 (57.8\%) \\
\hline All & 12823 & $4946(38.6 \%)$ & 3497 & $1857(53.1 \%)^{*}$ \\
\hline Mean (SD) & $53.0(8.3)$ & $38.6 \% \dagger$ & $56.8(6.7)^{*}$ & $51.5 \% \dagger$ \\
\hline
\end{tabular}

notification. Offspring follow the ethnic group of the father There are three major ethnic groups in Singapore: Chinese, Malays, and Indians, who are descendants of immigrants from China, the Malaysian Archipelago, and the Indian subcontinent, respectively. While intermarriage between ethnic groups was infrequent, the practice is becoming more common. Other ethnic groups, including Eurasians, are small $(1.5 \%)$ and were excluded from analysis. Symptoms were classified as typical if chest pain, or a similar description, was the principal symptom of MI lasting for $\geqslant 20$ minutes. A history of MI was obtained from the patient history or medical records. ECGs were read according to the Minnesota criteria. ${ }^{12}$ Information on history and ECG was not available for patients who died before hospitalisation.

Patients were classified according to a local modification of the MONICA algorithm ${ }^{13}$ under one of nine diagnostic categories, as previously reported. ${ }^{11}$ While the SMIR was restricted only to those with definite MI, the present study included patients with diagnostic categories of definite acute MI (MONICA NFl category) or clinical acute MI, and death from MI with or without necropsy (MONICA F1, F2, and F9 categories). This paper reports the findings for the period from 1991 to 1999.

\section{Invasive cardiac procedures}

The Central Claims and Processing System of the Ministry of Health was established in 1990 for payment of hospital charges, including surgical procedure fees. For almost all residents, part of the payment is derived from a compulsory savings scheme and it is routinely audited to ensure accuracy of data collection. Specific charge codes were designed to capture the use of each invasive cardiac procedure-namely, coronary angiography, coronary angioplasty, and coronary artery bypass grafting. The date of the procedure was also entered. To determine whether and when the patient had undergone an invasive cardiac procedure, the SMIR was linked to this system until 31 December 2000.

\section{Linkage to the registry of births and deaths}

Besides providing a source for identification of cases, the SMIR is linked to the Registry of Births and Deaths to determine the vital status of each patient. Previous studies have documented the completeness of this information source. $^{14}$ The last date of follow up for this report was 31 December 2000.

\section{Statistical analysis}

SPSS for Windows version 10 (SPSS Inc, Chicago, Illinois, USA) was used for data management and analysis. Several internal checks were set up in the database to ensure information quality.

$\chi^{2}$ Tests were used to analyse differences in categorical variables and analysis of variance for continuous variables. Age was analysed as a continuous variable and was stratified into two groups: $20-54$ years and 55-64 years. Kaplan-Meier estimates were performed for long term survival, with the log rank test for comparison between groups. Cox regression analysis was applied to predict survival outcomes by sex, age, and ethnic groups. Among hospitalised patients, the following covariates were used to adjust for the sex difference estimate in the Cox model: age, symptoms, peak CK concentration, history of previous MI, Q wave MI, and use of revascularisation procedures within 28 days. Interactions between either sex or age and ethnic groups were tested by introduction of product terms.

\section{RESULTS}

There were 16320 acute coronary events, of which 12823 $(78.6 \%)$ occurred in men. Table 1 shows the distribution of acute coronary event and case fatality by age and sex. Women were older than men $(56.8 \vee 53.0$ years, $\mathrm{p}<0.001)$. The number of events was 10-fold higher in men than in women between the ages of 20-34 years but this difference declined to about twofold for those between 60-64 years. Overall, the 28 day age adjusted case fatality rate was higher for women (51.5\% v 38.6\%, p < 0.001 , odds ratio $1.81,95 \%$ confidence

Table 2 Twenty eight day case fatality occurring before or after hospitalisation by ethnic group and sex

\begin{tabular}{|c|c|c|c|c|c|c|c|c|c|}
\hline \multirow[b]{2}{*}{ Timing of death } & \multicolumn{3}{|l|}{ Chinese } & \multicolumn{3}{|l|}{ Indians } & \multicolumn{3}{|l|}{ Malays } \\
\hline & Men & Women & OR $(95 \% \mathrm{Cl})$ & Men & Women & OR (95\% Cl) & Men & Women & OR $(95 \% \mathrm{Cl})$ \\
\hline $\begin{array}{l}\text { Before } \\
\text { hospitalisation } \\
\text { After } \\
\text { hospitalisation } \\
\text { Total }\end{array}$ & $\begin{array}{l}28.9 \% \\
(2317 / 8028) \\
14.3 \% \\
(816 / 5711) \\
39.0 \% \\
(3133 / 8028)\end{array}$ & $\begin{array}{l}36.6 \% \\
(753 / 2055) \\
21.6 \% \\
(281 / 1302) \\
50.3 \% \\
(1034 / 2055)\end{array}$ & $\begin{array}{l}1.43 \\
(1.29 \text { to } 1.58) \\
1.65 \\
(1.42 \text { to } 1.92) \\
1.58 \\
(1.44 \text { to } 1.74)\end{array}$ & $\begin{array}{l}26.2 \% \\
(597 / 2282) \\
14.0 \% \\
(236 / 1685) \\
37.3 \% \\
(833 / 2282)\end{array}$ & $\begin{array}{l}35.5 \% \\
(205 / 577) \\
22.3 \% \\
(83 / 372) \\
49.9 \% \\
(288 / 577)\end{array}$ & $\begin{array}{l}1.56 \\
(1.28 \text { to } 1.89) \\
1.76 \\
(1.33 \text { to } 2.33) \\
1.73 \\
(1.44 \text { to } 2.08)\end{array}$ & $\begin{array}{l}29.2 \% \\
(670 / 2294) \\
14.3 \% \\
(232 / 1624) \\
39.3 \% \\
(902 / 2294)\end{array}$ & $\begin{array}{l}50.6 \% \\
(410 / 811) \\
24.7 \% \\
(99 / 401) \\
62.8 \% \\
(509 / 811)\end{array}$ & $\begin{array}{l}2.48 \\
(2.10 \text { to } 2.92) \\
1.97 \\
(1.51 \text { to } 2.57) \\
2.60 \\
(2.20 \text { to } 3.07)\end{array}$ \\
\hline
\end{tabular}



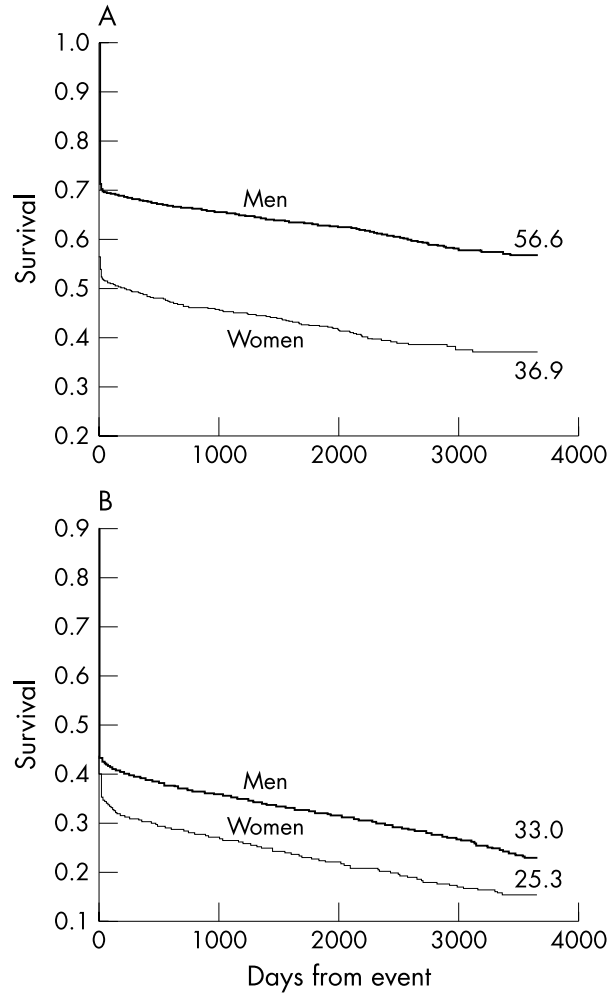

Figure 1 Kaplan-Meier plots showing long term survival after onset of an acute coronary event in the community for men and women between the ages of (A) 20-54 years $(p<0.0001)$ and (B) 55-64 years $(p<0.0001)$

interval (CI) 1.67 to 1.95 ). The patients comprised 10083 Chinese (61.8\%), 3105 Malays (19.0\%), and 2859 Indians (17.5\%); 273 patients (1.7\%) who belonged to other ethnic groups were excluded from subsequent analysis.

\section{Twenty eight day case fatality from symptom onset:} before and after admission to hospital

Overall, there was little difference between the two sexes in the proportion of deaths that took place before hospitalisation $(73.6 \%$ in men and $74.7 \%$ in women, $p=0.38$ ) (table 2 ). For men, this rate was similar among the three ethnic groups $(p=0.37)$. However, the proportion of deaths that occurred before hospitalisation among Malay women (80.6\%) was higher than among Chinese (72.8\%) and Indian women $(71.2 \%)(p=0.001)$. Regardless of ethnic group, 28 day case fatality among women was consistently higher than among men during both the pre-hospitalisation and post-admission periods. There was also significant ethnic variation in the degree of female excess in case fatality, with the Malays having the largest sex gap.

\section{Long term case fatality from symptom on set}

After a mean (SE) follow up period of 987 (9) days, the case fatality rate remained higher among women (fig 1A). The overall age-ethnic adjusted hazard ratio for the female excess in long term case fatality was 1.31 (95\% CI 1.24 to 1.37 , $\mathrm{p}<0.001$ ). There were also significant interactions between age, sex, and ethnic group $(\mathrm{p}=0.001)$. The degree of sex difference in survival diminished with age (fig lB). Malays had the largest gap (table 3). Young Malay patients had the greatest sex discrepancy in long term case fatality.

\section{Hospitalised MI patients}

The following analyses are restricted to patients who survived until hospital admission.

\section{Baseline characteristics}

Women admitted for MI were older, were less likely to have had a previous Q wave or anterior wall MI, and had lower peak CK concentrations (table 4). They were less likely to undergo coronary angiography within 28 days of the event, but the rate of coronary revascularisation was comparable between the two sexes.

\section{Case fatality rates after admission}

Overall, the age adjusted 28 day and one year case fatality rates were higher for women (table 4 ). The adjusted hazard ratios for 28 day and one year case fatality were 1.64 (95\% CI 1.43 to 1.88 ) and 1.56 (95\% CI 1.39 to 1.75$)$, respectively. Interaction between sex and ethnicity was not significant. After a mean (SE) follow up period of 1428 (10) days, the excess female case fatality persisted (adjusted hazard ratio $1.50,95 \%$ CI 1.37 to 1.64 ). However, there were significant interactions between age, sex, and ethnic group $(\mathrm{p}=0.017)$. The sex gap in long term case fatality diminished with age (fig 2 ). When only 28 day survivors were analysed, the long term mortality gap between men and women persisted (adjusted hazard ratio $1.40,95 \%$ CI 1.24 to 1.57 ).

Case fatality was generally similar among the three ethnic groups for men but differed for women, with the highest mortality among Malay women, an intermediate rate among Indian women, and the lowest rate among Chinese women. With increasing duration of follow up, the sex difference appeared to narrow for Chinese but to widen for Malays (table 5). Eventually, Malays had the largest sex discrepancy with women being almost twice as likely to die as men.

Table 3 Long term coronary mortality according to sex, ethnicity, and age group

\begin{tabular}{|c|c|c|c|c|c|c|}
\hline \multirow[b]{2}{*}{ Age group (years) } & \multicolumn{2}{|l|}{ Chinese } & \multicolumn{2}{|l|}{ Indians } & \multicolumn{2}{|l|}{ Malays } \\
\hline & $\overline{\text { Men }}$ & Women & $\overline{\text { Men }}$ & Women & $\overline{\text { Men }}$ & Women \\
\hline $20-54$ & $\begin{array}{l}37.2 \% \\
(1434 / 3859)\end{array}$ & $\begin{array}{l}52.0 \% \\
(291 / 560)\end{array}$ & $\begin{array}{l}37.3 \% \\
(466 / 1248)\end{array}$ & $\begin{array}{l}63.8 \% \\
(113 / 177)\end{array}$ & $\begin{array}{l}40.4 \% \\
(481 / 1190)\end{array}$ & $\begin{array}{l}71.7 \% \\
(167 / 233)\end{array}$ \\
\hline $\mathrm{HR} \dagger$ & $1.48(1.30 \text { to } 1.68)^{\star * *}$ & & $1.93(1.57 \text { to } 2.37)^{\star * *}$ & & $2.09(1.75 \text { to } 2.50)^{\star * *}$ & \\
\hline $55-64$ & $\begin{array}{l}58.4 \% \\
(2434 / 4169)\end{array}$ & $\begin{array}{l}64.7 \% \\
(968 / 1495)\end{array}$ & $\begin{array}{l}56.0 \% \\
(579 / 1034)\end{array}$ & $\begin{array}{l}62.8 \% \\
(251 / 400)\end{array}$ & $\begin{array}{l}61.4 \% \\
(678 / 1104)\end{array}$ & $\begin{array}{l}79.9 \% \\
(462 / 578)\end{array}$ \\
\hline $\mathrm{HR} \dagger$ & $1.14(1.05 \text { to } 1.22)^{\star *}$ & & $1.63(1.27 \text { to } 2.10)^{*}$ & & $1.50(1.33 \text { to } 1.69)^{\star * *}$ & \\
\hline $20-64$ & $\begin{array}{l}48.2 \% \\
(3868 / 8028)\end{array}$ & $\begin{array}{l}61.3 \% \\
(1259 / 2055)\end{array}$ & $\begin{array}{l}45.8 \% \\
(1045 / 2282)\end{array}$ & $\begin{array}{l}63.1 \% \\
(364 / 577)\end{array}$ & $\begin{array}{l}50.5 \% \\
(1159 / 2294)\end{array}$ & $\begin{array}{l}77.6 \% \\
(629 / 811)\end{array}$ \\
\hline Age adjusted HR† & $1.19(1.12 \text { to } 1.27)^{\star \star \star}$ & & $1.35(1.20 \text { to } 1.53)^{\star * *}$ & & $1.62(1.47 \text { to } 1.79)^{\star * *}$ & \\
\hline
\end{tabular}

†Cox regression $(95 \% \mathrm{Cl})$

${ }^{*} \mathrm{p}=0.041 ;{ }^{* *} \mathrm{p}=0.001 ;{ }^{* * *} \mathrm{p}<0.001$

$\mathrm{HR}$, hazard ratio. 


\begin{tabular}{|c|c|c|c|}
\hline Characteristic & Men $(n=9016)$ & Women $(n=2074)$ & $\begin{array}{l}\text { Age adjusted rates } \\
\text { for women* }\end{array}$ \\
\hline Age (years) $\dagger$ & $53(46,59)$ & $58(53,62) \ddagger$ & \\
\hline \multicolumn{4}{|l|}{ Ethnic group } \\
\hline Chinese & $5710(63.3 \%)$ & $1302(62.8 \%)$ & \\
\hline Indian & $1624(18.0 \%)$ & $401(19.3 \%)$ & \\
\hline Malay & $1682(18.7 \%)$ & $371(17.9 \%) \S$ & \\
\hline Typical symptoms & $6768(75.1 \%)$ & $1315(63.4 \%)$ & $64.4 \% \ddagger$ \\
\hline Previous MI & $1048(11.6 \%)$ & $198(9.5 \%)$ & $8.1 \% \ddagger$ \\
\hline$Q$ wave $M I$ & $6706(74.4 \%)$ & $1314(63.4 \%)$ & $63.1 \% \ddagger$ \\
\hline Anterior $Q$ wave $M I$ & 3387 (37.6\%) & $680(32.8 \%)$ & $33.6 \% \ddagger$ \\
\hline CK (U/I)† & $1189(617,2569)$ & $878(479,1737) \ddagger$ & \\
\hline $\begin{array}{l}\text { Angiography within } \\
28 \text { days }\end{array}$ & $3434(38.1 \%)$ & $634(30.6 \%)$ & $33.1 \% \ddagger$ \\
\hline $\begin{array}{l}\text { Revascularisation within } \\
28 \text { days }\end{array}$ & 1385 (15.4\%) & $288(13.9 \%)$ & $15.0 \% \S$ \\
\hline 28 day case fatality & $1284(14.2 \%)$ & $463(22.3 \%)$ & $22.0 \% \ddagger$ \\
\hline 1 year case fatality & $1666(18.5 \%)$ & $604(29.1 \%)$ & $28.0 \% \ddagger$ \\
\hline
\end{tabular}

\section{DISCUSSION}

We found that the acute coronary event case fatality rate was consistently higher for women than for men, during the periods both before and after hospitalisation and among 28 day survivors. The sex disparity persisted after a mean follow up period of 2.7 years. Despite an upper age limit of 64 years, there was evidence for a diminishing strength of association with age. With an increasing number of older women having an MI, the sex discrepancy is expected to reduce further. We also found a significant interaction between ethnic group, age, and sex for long term survival. The sex discrepancy was particularly evident for younger patients and smallest among Chinese patients.

\section{Pre-hospitalisation and post-admission deaths}

An earlier study of 5542 patients in the Glasgow MONICA centre attributed the female excess in coronary mortality among hospitalised patients ${ }^{8}$ to a higher proportion of men dying suddenly before hospitalisation, with the less vulnerable men surviving to be admitted. After hospital admission, more women died than men, resulting in a similar overall 28 day case fatality. Results from MONICA population registries for ages 35-64 years were conflicting. ${ }^{9}$ Among 29 populations studied, 28 day case fatality was higher among women in 13 $(45 \%)$. When the studies were taken together, women were still more likely to die with an age adjusted ratio of 1.07 and of 1.24 for hospitalised patients. In contrast with the Scottish MONICA, our study found that women were more likely to die both before and after hospitalisation, although the disparity was greater after hospitalisation. These differences persisted after adjusting for age and ethnicity in our population. While the response to reperfusion treatment was similar between the two sexes, ${ }^{15}$ the adjusted 30-35 day mortality was still higher among women in two large international trials comprising more than 77000 patients. ${ }^{76}$

\section{Hospitalised patients}

The magnitude of the 28 day case fatality rate was consistent with most of the MONICA populations. ${ }^{9}$ Several studies have reported that long term mortality among survivors of MI are similar or lower among women, ${ }^{17-19}$ especially among older patients. ${ }^{20}$ In a study of hospitalised MI survivors in the USA, ${ }^{6}$ two year mortality was higher among women $<60$ years, whereas women $\geqslant 80$ years old were less likely to die. We found that one year and four year case fatality rates of hospitalised patients were greater among younger women and that the extent of the sex difference in long term mortality diminished with age. Of concern was that the sex disparity in long term mortality after MI persisted among 28 day survivors. The reasons for the excess mortality are uncertain and have been attributed to adverse baseline characteristics. ${ }^{20}$ However, other investigators ${ }^{6}$ reported that the higher mortality among younger women persisted after controlling for inequalities in clinical condition and severity of MI. Coronary artery disease occurs less frequently among women. ${ }^{21}$ For MI to develop in young women, there must be substantial loss of protection, which might also have resulted in poorer outcome. ${ }^{22}$
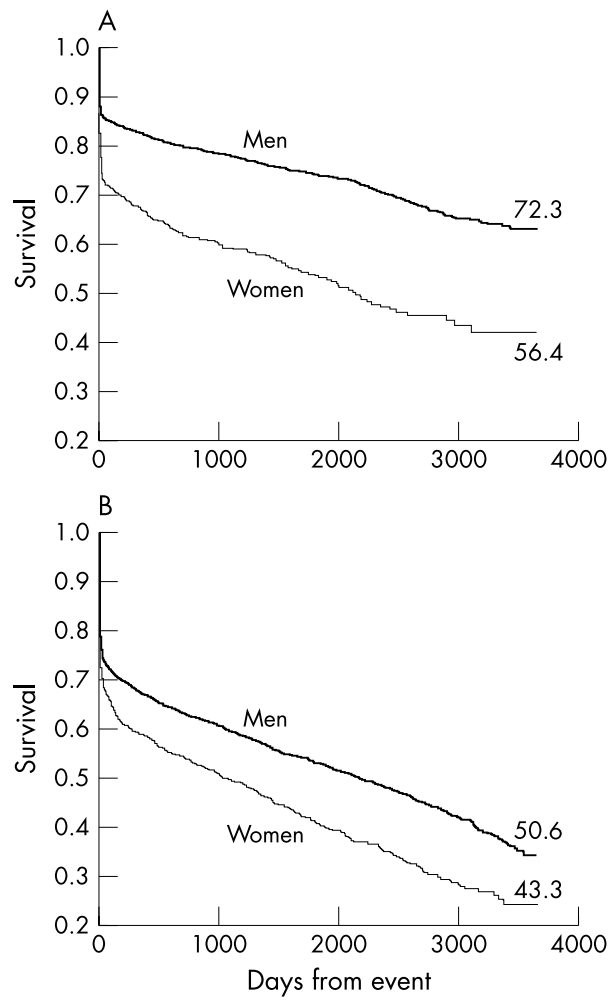

Figure 2 Kaplan-Meier plots showing long term survival after admission for a myocardial infarction event in men and women between the ages of (A) 20-54 years $(p<0.0001)$ and (B) 55-64 years $(p<0.0001)$. 
Table 5 Case fatality rates among hospitalised patients according to sex and ethnic group

\begin{tabular}{|c|c|c|c|c|c|c|}
\hline \multirow[b]{2}{*}{ Case fatality } & \multicolumn{2}{|l|}{ Chinese } & \multicolumn{2}{|l|}{ Indians } & \multicolumn{2}{|l|}{ Malays } \\
\hline & $\operatorname{Men}(n=5710)$ & Women $(n=1302)$ & Men $(n=1682)$ & Women $(n=371)$ & Men $(n=1624)$ & Women $(n=401)$ \\
\hline $\begin{array}{l}28 \text { days* } \\
\text { Adjusted† HR }\end{array}$ & $\begin{array}{l}816(14.3 \%) \\
1.59(1.33 \text { to } 1.89)\end{array}$ & $281(21.6 \%)$ & $\begin{array}{l}236(14.0 \%) \\
1.67(1.20 \text { to } 2.32)\end{array}$ & $83(22.4 \%)$ & $\begin{array}{l}232(14.3 \%) \\
1.75(1.29 \text { to } 2.38)\end{array}$ & $99(24.7 \%)$ \\
\hline $\begin{array}{l}1 \text { year }^{* *} \\
\text { Adjusted† HR }\end{array}$ & $\begin{array}{l}1041(18.2 \%) \\
1.46(1.26 \text { to } 1.70)\end{array}$ & $352(27.0 \%)$ & $\begin{array}{l}305(18.1 \%) \\
1.69(1.28 \text { to } 2.21)\end{array}$ & $110(29.6 \%)$ & $\begin{array}{l}320(19.7 \%) \\
1.71(1.34 \text { to } 2.18)\end{array}$ & $142(35.4 \%)$ \\
\hline $\begin{array}{l}\text { Long term }{ }^{* * *} \\
\text { Adjusted† HR }\end{array}$ & $\begin{array}{l}1551(27.2 \%) \\
1.30(1.15 \text { to } 1.46)\end{array}$ & $506(38.9 \%)$ & $\begin{array}{l}448(26.6 \%) \\
1.71(1.38 \text { to } 2.12)\end{array}$ & 159 (42.9\%) & $\begin{array}{l}489(30.1 \%) \\
1.96(1.62 \text { to } 2.35)\end{array}$ & $219(54.6 \%)$ \\
\hline
\end{tabular}

$\mathrm{p}$ Value for sex-ethnic group interaction ${ }^{*} 0.58,{ }^{* *} 0.11,{ }^{* * *} 0.017$

tThe variables that were adjusted for in the Cox model were age, typical symptoms, history of previous $\mathrm{MI}$, peak CK concentration, Q wave MI, and use of revascularisation procedures within 28 days.

$95 \% \mathrm{Cl}$ in parentheses.

\section{Sex, age, and ethnicity}

While an earlier review, ${ }^{3}$ based largely on hospitalised patients, concluded that early mortality among women was not substantially increased after adjusting for baseline characteristics, reports based on large databases showed that women were at a higher risk of dying after MI, ${ }^{53}$ especially younger patients. Similar mortality was observed between men and women among those $\geqslant 75$ years in the National Registry of Myocardial Infarction 2 (NRMI-2) $)^{5}$ and among patients $\geqslant 65$ years in Medicare's cooperative cardiovascular project. ${ }^{24}$ Recently, the Swedish national acute myocardial infarction register ${ }^{20}$ reported that 28 day case fatality was higher among women $<50$ years old (odds ratio 1.31 , 95\% CI 1.18 to 1.46 ). Similarly, we found that the age-sex interaction in case fatality was operative in a population registry and that the effect persisted during follow up. In addition, our population based registry had wide disparities in the female excess in coronary mortality among the three ethnic groups. While the age-sex relation was preserved in each ethnic group, Malays consistently had the greatest difference. In addition, we have found a significant interaction between sex and ethnicity on long term follow up. Of the three ethnic groups, the sex difference in long term case fatality was largest among Malays followed by Indians and then Chinese. These sex differences across ethnic groups were predominantly caused by inequalities in female survival, whereas ethnic differences in male case fatality were modest. The explanations for these discrepancies are unclear. It is likely that other factors, such as cultural, psychosocial, socioeconomic, and possibly other biological factors, ${ }^{25}$ are operating for the sex difference to continue to diverge among hospitalised Malay patients. Our registry lacked data on risk and prognostic factors such as diabetes, which has been consistently associated with poorer outcome. ${ }^{26}$ Nonetheless, our national health survey from $1998^{27}$ provides some insight. The sex difference in prevalence of diabetes was greatest for Malays ( $14.3 \% v 8.2 \%)$ compared with Chinese $(8.4 \%$ v $7.7 \%)$ and Indians $(14.9 \% v 16.7 \%)$. Another reason may relate to the more frequent atypical presentation of MI among women than men (35.6\% $v 24.9 \%$ in the SMIR), which may have delayed seeking medical attention and prolonged the time to receiving life saving treatments, ${ }^{28}$ particularly among young Malay women. Willingness to seek medical attention ${ }^{29}$ and undergo procedures that may potentially improve long term outcome may also partly explain the disparity. In the USA, African Americans were less inclined to undergo cardiac procedures in the coronary care $\mathrm{unit}^{30}$ or to consent to percutaneous coronary intervention ${ }^{31}$ and coronary artery bypass grafting. ${ }^{32}$ In Finland, the incidences of MI and 28 day and one year case fatality were significantly higher among those in the lower income groups and with only secondary education. ${ }^{33}$ Similarly, male patients with little education were more likely to die suddenly after MI. ${ }^{34}$ From 1990 to
2000 , the proportion with tertiary education rose from 5.3\% to $19.6 \%$ among Indians, from $9.2 \%$ to $19.6 \%$ among Chinese, and from only $1.5 \%$ to $4.9 \%$ for Malays in Singapore. ${ }^{35}$

For several years, extensive public education programmes on heart attack have been conducted throughout the country. The annual healthy lifestyle campaign is a nationwide event designed to promote healthy living and eating habits among Singaporeans. Several strong disincentives have been established to curb tobacco abuse. Risk factors for atherosclerosis and the clinical manifestations of MI are even taught to young school children. Despite these efforts, wide sex and ethnic disparities persist in a relatively close knit and affluent society with a freely accessible health care system. The impact of adverse behavioural patterns, psychosocial and biological factors, and socioeconomic and educational status requires further study.

\section{ACKNOWLEDGEMENTS}

The SMIR was funded partly by the Singapore National Heart Association. We also thank Ms Caren Tan for her assistance.

The data were presented in part in the 50th Annual Scientific Meeting of the American College of Cardiology.

\section{Authors' affiliations}

K H Mak, L L Sim, Z P Ding, R Kam, Department of Cardiology, National Heart Centre, Singapore

J D Kark, Epidemiology Unit, Hebrew University-Hadassah School of Public Health and Community Medicine, Jerusalem, Israel

K S Chia, Department of Community, Family and Occupational Medicine, National University of Singapore

B H Foong, S K Chew, Division of Epidemiology and Disease Control, Ministry of Health, Singapore

\section{REFERENCES}

1 Jenkins JS, Flaker GC, Nolte B, et al. Causes of higher in-hospital mortality in women than in men after acute myocardial infarction: the Framingham study. Am J Cardiol 1994;73:319-22.

2 Marrugat J, Gil M, Masiá R, et al. Mortality differences between men and women following first myocardial infarction. RESCATE Investigators. Recursos Empleados en el Sindrome Coronario Agudo y Tiempo de Espera. JAMA 1998;280: 1405-9.

3 Vaccarino V, Krumholz HM, Berkman LF, et al. Sex differences in mortality after myocardial infarction: is there evidence for an increased risk for women? Circulation 1995;91:1861-71.

$4 \mathrm{He} \mathrm{J}$, Klag MJ, Whelthon PK, et al. Short-and long-term prognosis after acute myocardial infarction in Chinese men and women. Am J Epidemiol 1994; 139:693-703.

5 Vaccarino V, Parsons L, Every NR, et al. Sex-based differences in early mortality after myocardial infarction. National registry of myocardial infarction 2 participants. N Engl J Med 1999;341:217-25.

6 Vaccarino V, Krumholz HM, Yarzebski J, et al. Sex differences in 2-year mortality after hospital discharge for myocardial infarction. Ann Intern Med $2001 ; 134: 173-81$

7 Malacrida R, Genoni M, Maggioni AP, et al. A comparison of the early outcome of acute myocardial infarction in women and men. The third international study of infarct survival collaborative group. $N$ Engl J Med 1998;338:8-14.

8 Tunstall-Pedoe H, Morrison C, Woodward M, et al. Sex differences in myocardial infarction and coronary deaths in the Scottish MONICA 
population of Glasgow 1985-91: presentation, diagnosis, treatment, and 28day case fatality of 3991 events in men and women. Circulation 1996;93:1981-92.

9 Chambless L, Keil U, Dobson A, et al. Population versus clinical view of case fatality from acute coronary heart disease: results from the WHO MONICA project 1985-1990. Circulation 1997;96:3849-59.

10 Mak K-H, Chia KS, Kark JD, et al. Ethnic differences in acute myocardial infarction in Singapore. Eur Heart J 2003;24:151-60.

11 Emmanuel SC, Tan ATH, Tunstall-Pedoe H, et al. The operational research study for the Singapore myocardial infarction register. Sing Med J 1988;29:446-57.

12 Blackburn H, Keys A, Simonson E, et al. The electrocardiogram in population studies: a classification system. Circulation 1960;21:1160.

13 Tunstall-Pedoe H, Kuulasmaa K, Amouyel $\mathrm{P}$, et al. Myocardial infarction and coronary deaths in the World Health Organization MONICA project: registration procedures, event rates and case fatality in 38 populations from 21 countries in 4 continents. Circulation 1994;90:583-612.

14 Hughes K, Lun KC, Yeo PPB. Cardiovascular diseases in Chinese, Malays, and Indians in Singapore. I. Differences in mortality. J Epidemiol Community Health 1990:44:24-8.

15 Woodfield SL, Lundergan CF, Reiner JS, et al. Gender and acute myocardia infarction: is there a different response to thrombolysis? J Am Coll Cardiol 1997; 29:35-42

16 Weaver WD, White HD, Wilcox RG, et al. Comparisons of characteristics and outcomes among women and men with acute myocardial infarction treated with thrombolytic therapy. JAMA 1996;275:777-82.

17 White HD, Barbash GI, Modan M, et al. After correcting for worse baseline characteristics, women treated with thrombolytic therapy for acute myocardia infarction have the same mortality and morbidity as men except for a higher incidence of hemorrhagic stroke. The investigators of the international tissue plasminogen activator/streptokinase mortality study. Circulation 1993;88:2097-103

18 Kostis JB, Wilson AC, O'Dowd K, et al. Sex differences in the management and long-term outcome of acute myocardial infarction: a statewide study. Circulation 1994;90:1715-30.

19 Maynard C, Every NR, Martin JS, et al. Association of gender and survival in patients with acute myocardial infarction. Arch Intern Med 1997; 157:1379-84.

20 Rosengren A, Spetz C-L, Köster $M$, et al. Sex differences in survival after myocardial infarction in Sweden. Eur Heart J 2001;22:314-22.

21 Lerner DJ, Kannel WB. Patterns of coronary heart disease morbidity and mortality in the sexes: a 26-year follow-up of the Framingham population. Am Heart J 1986;111:383-90.
22 Wexler LF. Studies of acute coronary syndromes in women: lessons for everyone. N Engl J Med 1999;341:275-6.

23 Vaccarino V, Hortwitz RI, Meehan TP, et al. Sex differences in mortality after myocardial infarction: evidence for a sex-age interaction. Arch Intern Med 1998:158:2054-62

24 Gan SC, Beaver SK, Houck PM, et al. Treatment of acute myocardial infarction and 30-day mortality among women and men. N Engl J Med 2000;343:8-15.

25 Ayanian JF. Increased mortality among middle-aged women after myocardial infarction: searching for mechanisms and solutions. Ann Intern Med 2001;134:239-41.

26 Mak K-H, Topol EJ. Emerging concepts in the management of acute myocardial infarction in patients with diabetes mellitus. J Am Coll Cardio 2000;35:563-8.

27 Anon. Epidemiology and Disease Control Department. National health survey 1998. Singapore: Ministry of Health, 1999.

28 Barakat K, Wilkinson P, Suliman A, et al. Acute myocardial infarction in women: contribution of treatment variables to adverse outcome. Am Heart $J$ 2000;140:740-6.

29 Hemingway H, Malik M, Marmot M. Social and psychosocial influences on sudden cardiac death, ventricular arrhythmia and cardiac autonomic function. Eur Heart J 2001;22:1082-101.

30 Schecter AD, Goldschmidt-Clermont PJ, McKee G, et al. Influence of gender, race, and education on patient preferences and receipt of cardiac catheterizations among coronary care unit patients. Am J Cardiol 1996;78:996-1001.

31 Whittle J, Conigliaro J, Good CB, et al. Do patient preferences contribute to racial differences in cardiovascular procedure use? J Gen Intern Med 1997; 12:267-73.

32 Peterson ED, Shaw LK, DeLong ER, et al. Racial variation in the use of coronary-revascularization procedures. Are the differences real? Do they matter? N Engl J Med 1997;336:480-6.

33 Salomaa V Niemela $M$, Miettinen $\mathrm{H}$, et al. Relationship of socioeconomic status to the incidence and prehospital, 28-day, and 1-year mortality rates of acute coronary events in the FINMONICA myocardial infarction register study. Circulation 2000;101:1913-8.

34 Weinblatt E, Ruberman W, Goldberg JD, et al. Relation of education to sudden death after myocardial infarction. $N$ Engl J Med 1978;299:60-5.

35 Leow BG. Census of population release 2: education, language and religion. Department of Statistics, Ministry of Trade and Industry, Singapore, 2001

\section{IMAGES IN CARDIOLOGY}

\section{Cardiac haematoma after coronary angioplasty}

A 65 year old man presented with chest discomfort accompanied by ST elevation in leads Vl-V5 on an ECG. Coronary angiography revealed severe stenosis in the mid portion of the left anterior descending artery (panel A, arrowhead). During percutaneous coronary intervention, a 0.014 inch guidewire was inserted into the septal perforator branch, leading to persistent extravasation of contrast media (panel B). Prolonged balloon inflation in the septal perforator and a reversal of anticoagulation resulted in a haemostasis with difficulty. Subsequent echocardiography showed a newly developed homogenous bulge proceeding from the septal wall (panels $\mathrm{C}$ and D: LA, left atrium; LV, left ventricle), with no accumulation of pericardial fluid. Fortunately, neither haemodynamic deteriorations nor elevations of cardiac enzymes occurred during the clinical course of this unfavourable complication. The huge haematoma in his heart was gradually resorbed and disappeared completely several weeks later.

S Asada

T Kawasaki

H Sugihara

sa-asada@mbox.kyoto-inet.or.jp
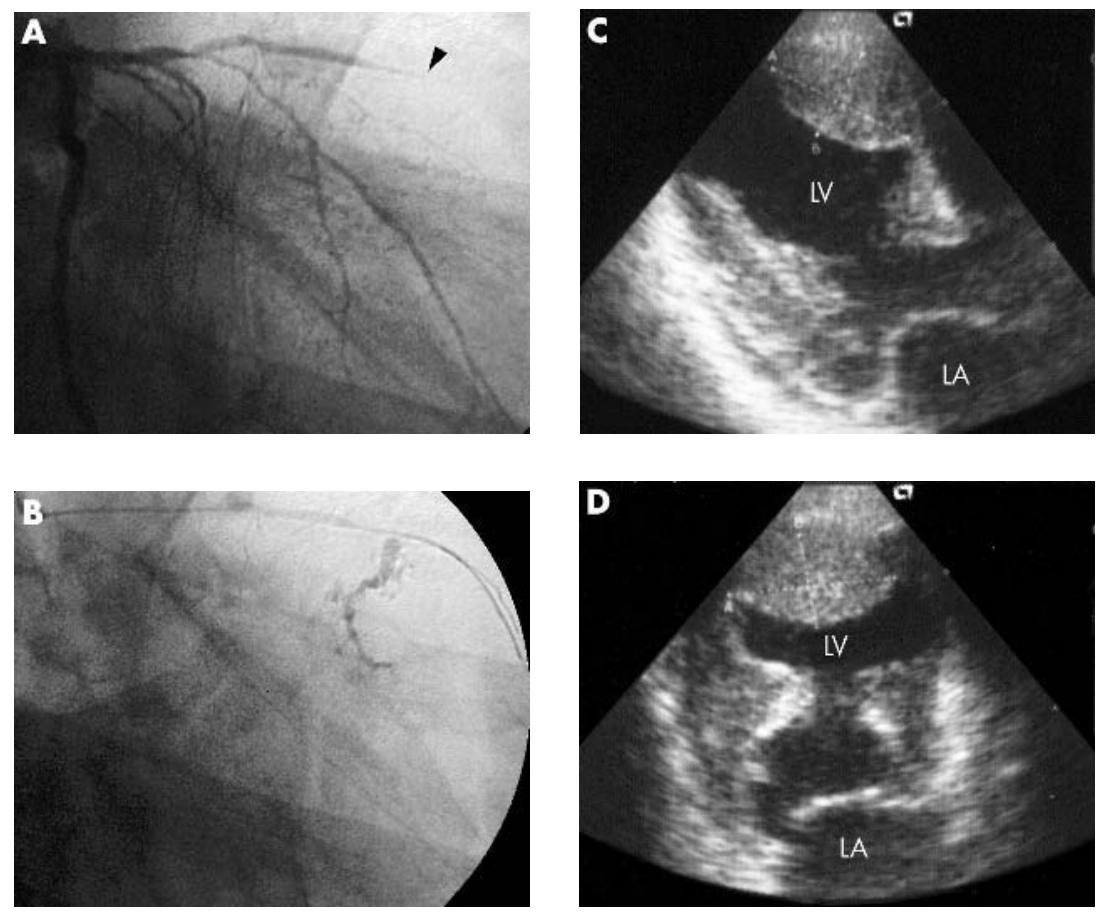